Original article

\title{
Influence of the Promixan Probiotic on Productivity of Growing Pigs from the East Balkan Swine Breed
}

\author{
Gergana Yordanova (1) a, ", Nadezhda Palova (i) b \& Radka Nedeva (i) a \\ ${ }^{a}$ Agricultural Institute - Shumen, Bulgaria \\ ${ }^{\circ}$ Scientific Center for Agriculture - Sredets, Bulgaria
}

\begin{abstract}
An experiment with growing pigs of the East Balkan pig breed was conducted at the Scientific Center for Agriculture in Sredets, Bulgaria. The animals were divided into two groups (trial - I group and control - II group) of 10 animals in a group or a total of 20 pigs. The experiment started immediately after weaning, at a live weight of $8.320-8.390 \mathrm{~kg}$ and ended at $24.260-23.340 \mathrm{~kg}$ live weight. The pigs were fed with cereals (barley and wheat in a ratio of 50:50) with a content of $13 \%$ crude protein in $\mathrm{kg}$ daily ration. Promixan probiotic was added to the feed of the first (trial) group in the amount of $50 \mathrm{~g}$ per $100 \mathrm{~kg}$ of feed.

The aim of the experiment was to determine the effect of the probiotic Promixan on productivity and health in growing pigs of the East Balkan pig breed.

The addition of $50 \mathrm{~g}$ per $100 \mathrm{~kg}$ feed of Promixan probiotic to the ration of growing pigs (from 8.3-8.4 kg to $23.3-24.3 \mathrm{~kg}$ live weight) from the East Balkan swine breed significantly increased the growth intensity by $6.13 \%(P<0.01)$ and improved the feed conversion by $5.78 \%$.
\end{abstract}

Keywords: Growing Pigs, Probiotic, Productivity, East Balkan Swine.

Received: 28 October $2021 \quad * \quad$ Accepted: 01 December $2021 \quad * \quad$ Dol: https://doi.org/10.29329/ijiaar.2021.415.9

\footnotetext{
* Corresponding author:

Yordanova Gergana is a chief assistant professor in the Livestock breeding Department of Agricultural Institute - Shumen, Bulgaria.. Her research interests include the pig breeding and nutrition.

Email: gerganaarshspb@abv.bg
} 


\section{INTRODUCTION}

Pathogenic microorganisms are a potential threat to the agricultural and food industries. Food contamination can occur at production levels at any point in the chain of pathogenic microorganisms. Conventional methods, such as those involving antibiotics, disinfectants, and physical methods, are commonly used as microbial control strategies. Due to the limitations of these methods, such as the emergence of resistance, low efficiency, high cost and harmful effects on food, health and the environment, many countries have adopted laws and regulations restricting their use. To overcome these problems, an environmentally friendly, cost-effective alternative approach is urgently needed. Probiotics are living microorganisms that offer benefits to the health of the host when consumed in adequate amounts, providing protective action of the pathogen and nutritional benefits (Hossain et al, 2017).

Probiotics are used in all different production phases of pig breeding. They are used for many purposes, such as improving productivity, mitigating diseases, improving product quality or reducing environmental pollutants. Taken that into account, their use is still not a tendency in the pig breeding industry. Probiotics are perceived skeptically by many nutritionists because of their highly variable results and unpredictability when used empirically (Barba - Vidal et al. 2019). Given the harmful effects of feed antibiotics and their irresponsible use in veterinary practice, probiotics have a good chance as a viable alternative prophylactic and therapeutic agent in animal husbandry (Alayandeet al. 2020).

The use of some probiotic microorganisms has a promising therapeutic approach to reduce the risk of inflammatory bowel disease. Several mechanisms have been proposed to explain the benefits of probiotics, indicating that some bacterial strains are able to positively modulate the intestinal microbiota and immune system and produce metabolites with anti-inflammatory properties (Celiberto et al. 2017).

In an experiment with growing pigs, Zhao and Kim (2015) found that the inclusion in a combination of $0.1 \%$ complex of $L$. reuteri and L. plantarum $(1 \times 109 \mathrm{cfu} / \mathrm{kg})$ improved the digestibility of $\mathrm{N}$ and GE, increased the concentration of fecal lactobacilli in the faeces, reduced diarrhea, faecal emissions and the concentration of E. coli in weaned pigs.

The ability of probiotics to modulate the immune system is one of the latest developments in animal husbandry. In the study by Ahmed et al. (2014) immune responses were assessed by determining the levels of serum immunoglobulins (IgG, IgM and IgA) and the cytokine TNF- $\alpha$. The results show that serum IgG levels are significantly increased in the group treated with Bacillus probiotics.

The new challenges in probiotic research are the creation of modern forms of food, supplements and therapeutics that meet the safety requirements - welfare, convenience and usefulness, ensuring optimal health for each individual. This will allow the creation of the so-called targeted probiotic preparations that will best meet the needs of consumers, without risk in their application. 
In our study, we used the probiotic Promixan, which is a combination of beneficial living microorganisms that have prophylactic and therapeutic effects, improving the internal microbial balance by colonizing the intestinal mucosa and producing vital enzymes and cellular bioproducts. We aimed to establish the effect of the Promixan probiotic on the productivity and health condition in growing pigs from the East Balkan swine breed.

\section{MATERIAL AND METHODS}

An experiment with growing pigs from the East Balkan swine breed was conducted in the Scientific Center for Agriculture - Sredets, Bulgaria. The animals were divided into two groups (Group I - trial and Group II - control) with 10 animals in each group or 20 animals in total. The experiment began immediately after weaning with $8.320-8.390 \mathrm{~kg}$ live weight and ended at $24.260-23.340 \mathrm{~kg}$ live weight. The pigs were fed cereals (barley and wheat in a ratio of 50:50) with a content of $13 \%$ crude protein in kg daily ration. Promixan probiotic was added to the feed of the first (experimental) group in the amount of $50 \mathrm{~g}$ per $100 \mathrm{~kg}$ of feed.

During the experiment the following were controlled: feed intake - daily, in groups by pens; daily gain - individually; feed conversion for kg gain - for the entire period (Table 1).

Table 1. Experimental scheme of the study

\begin{tabular}{|c|c|c|}
\hline Groups & $\begin{array}{c}\text { Trial } \\
\text { Supplement }\end{array}$ & $\begin{array}{c}\text { Control } \\
\text { (Group II) }\end{array}$ \\
\hline Number of animals & 10 & 10 \\
\hline Probiotic & $\begin{array}{c}\text { During the entire period } \\
50 \mathrm{~g} \text { for 100 } \mathrm{\kappa g} \text { feed }\end{array}$ & - \\
\hline
\end{tabular}

Promixan contains Lactobacillus acidophilu, Lactobacillus helveticus, Lactobacillus delbrueckii subsp. Bulgaricus NBIMCC 8244, Lactobacillus delbrueckii subsp. lactis, Streptococcus thermophilus, Enterococcus Faecium.

The results were statistically processed using computer statistical software. Using Excel and the descriptive statistics option, averages and standard deviations were determined for each indicator. The comparison of the values was performed using a computer statistical program Inner SAT, version 1.3. and the ANOVA option - one-factor analysis, and the degree of significance proven by Tukey test. The differences between the same indicators in the different groups were considered significant at $\mathrm{P}<0.05$.

\section{RESULTS AND DISCUSSION}

The pigs from the control and trail groups received the same amount of grain feed at $0.9 \mathrm{~kg}$ per animal per day. The animals from the trial group (I), which received Promixan with their daily ration, had a higher live weight $(24.26 \mathrm{~kg})$ at the end of the experiment (at the end of the growing period), 
compared with the control group-23.34kg. The difference between the groups of 3.94\% is statistically significant $(\mathrm{p}<0.01)$ (Fig. 1).

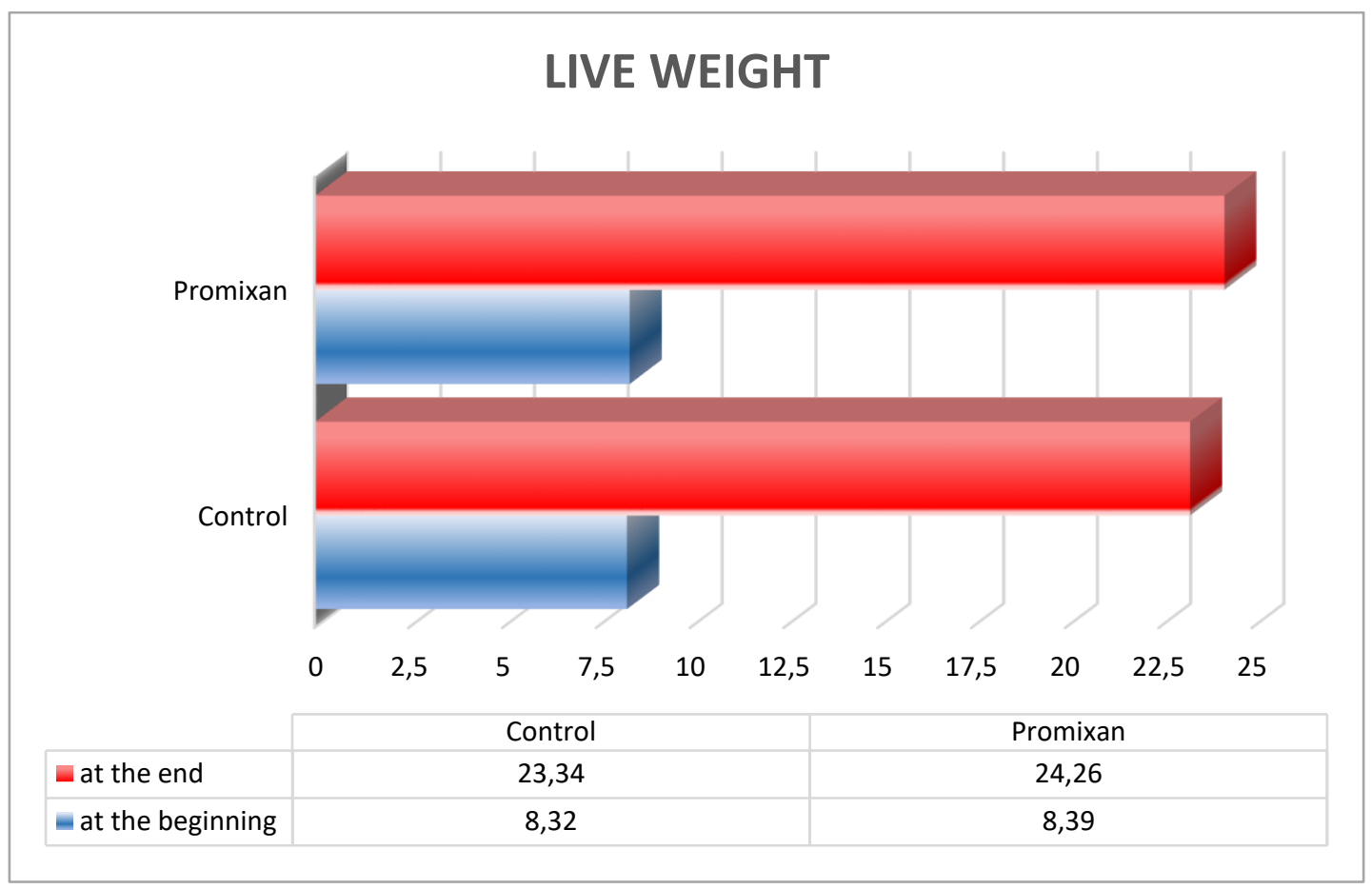

Figure 1. Live weight of animals

The analysis of the results indicated that in relation to the average daily gain, animals from the trial group which received probiotic in their rations had higher growth intensity with $6.13 \%(0.173$ $\mathrm{kg} /$ day compared to $0.163 \mathrm{~kg} /$ day). The difference is significant with $\mathrm{P}<0.01$ (Figure 2).

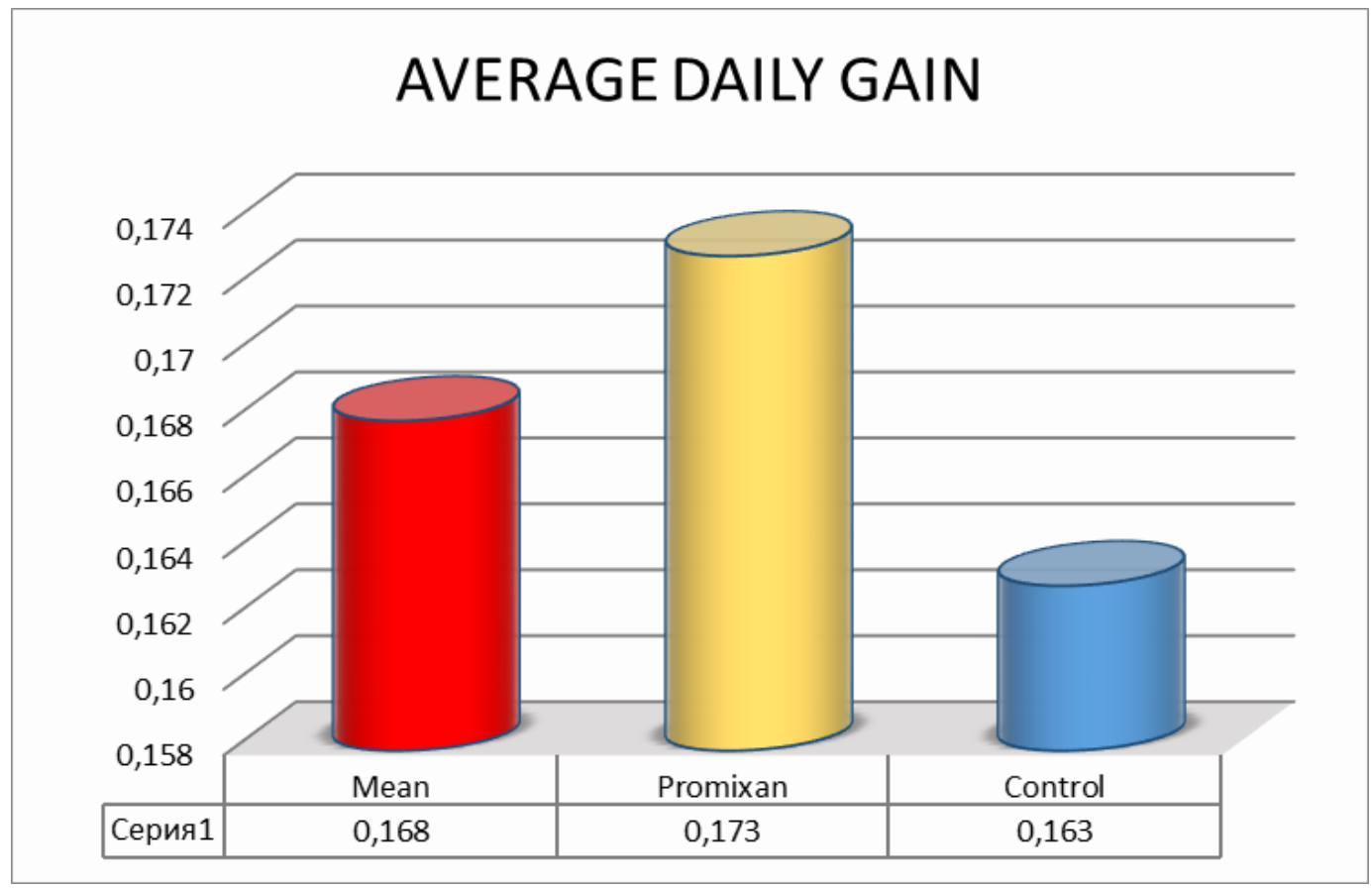

Figure 2. Average daily gain of animals 
Our results are similar to those obtained by Giang et al. (2010), who noted that the inclusion of $0.06 \%$ probiotic (Enterococcus faecium $6 \mathrm{H} 2$, Lactobacillus acidophilus $\mathrm{C} 3$, Pediococus pentosaceus D7, L. plantarum $1 \mathrm{~K} 8$ and L. plantarum $3 \mathrm{~K} 2$ ) had positive effects on average daily gain, daily feed intake and feed-growth ratio, in the first two weeks after weaning, but no effects were found in the following period.

Betancur et al. (2020) stated that after weaning, piglets have an immature immune and digestive system, which has consequences such as decreased activity of digestive enzymes, changes in intestinal morphology and reduced digestion in the small intestine. The authors reported that the caused immunodeficiency changes, the state of intestinal morphology after weaning allowed the growth of pathogens and increased the need for antibiotics, which in turn led to resistance. In this regard, the authors propose the use of probiotics after weaning to inhibit pathogenic bacteria, enhance the function of the intestinal microbiota and better immune development.

The East Balkan swine is the only autochthonous pig breeds in Bulgaria, which is traditionally fed by grazing and feeding (Palova et al. 2011). It has a phylogenetically determined ability to use natural trophic sources with low nutritional value (Danchev, 1984). Due to the nature of feeding the animals of the East Balkan breed, studies to test some nutritional factors used in conventional pig breeding have not been conducted or were too episodic (Palova, 2009; Palova et al. 2011; Kanev et al. 2013). Our results for live weight and growth intensity indicated that the added probiotic had a beneficial effect.

Regarding the feed conversion expressed by the consumption of feed per kg of growth, we reported lower values (by $5.78 \%$, Fig. 3) in piglets receiving added probiotics with their feed.

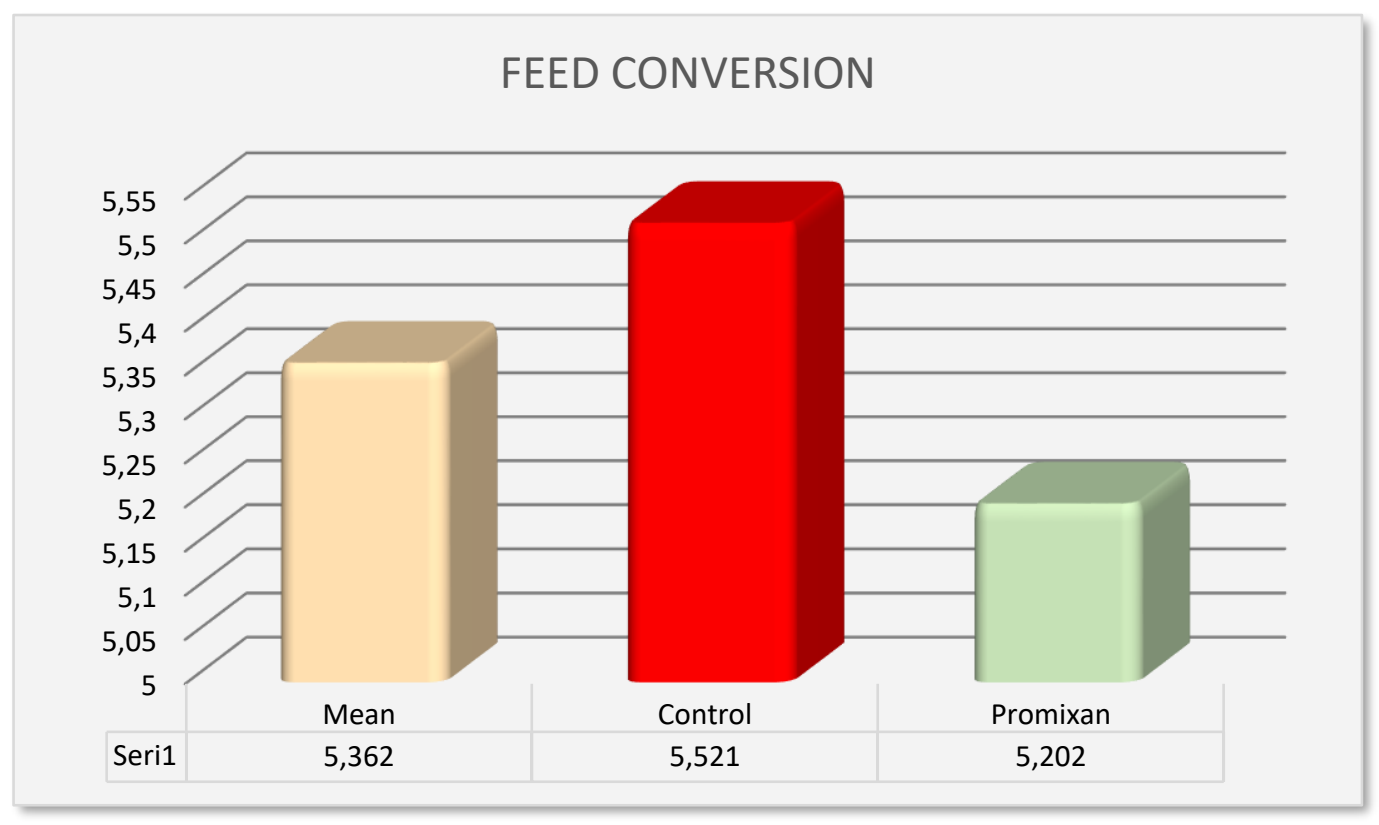

Figure 3. Feed conversion of animals 
Improved growth traits from the addition of probiotic bacteria were also studied by Alexopoulos et al. (2004) Shon et al. (2005), Ahmed et al. (2014), who reported better intestinal microbial balance and higher digestibility of nutrients.

In conclusion, the addition of the probiotic Promixan has a beneficial effect on the average daily gain and feed conversion of weaned pigs from the East Balkan swine breed.

\section{Conclusions}

The addition of $50 \mathrm{~g}$ per $100 \mathrm{~kg}$ feed of Promixan probiotic to the ration of weaned pigs (from 8.3-8.4 kg to 23.3-24.3 kg live weight) from the East Balkan swine breed significantly increased the average daily gain by $6.13 \%(\mathrm{P}<0.01)$ and improved the feed conversion ratio by $5.78 \%$.

\section{REFERENCES}

Ahmed, S. T., Ji Hoon, H. Mun, C. Yang, 2014. Evaluation of Lactobacillus and Bacillus- based probiotics as alternatives to antibiotics in enteric microbial challenged weaned piglets, African Journal of Microbiology Research, v.8. 1, 96-104.

Alayande, K. A., O. A. Aiyegoro, C. N. Ateba, 2020. Probiotics in Animal Husbandry: Applicability and Associated Risk Factors. Sustainability, 12(3), 1087.

Alexopoulos, C., Georgoulakis IE, Tzivara A., Kritas SK, Siochu A., Kyriakis SC, 2004. Field evaluation of the efficacy of a probiotic containing Bacillus licheniformis and Bacillus subtilisspores, on the health status and performance of sows and their litters. J. Anim. Physiol. Anim. Nutr. 88(11-12):381-392.

Barba-Vidal, E.S., M. Martín-Orúe,L. Castillejos, 2019. Practical aspects of the use of probiotics in pig production: A review, Livestock Science 223, May, 84-96.

Betancur, C., Y.Martinez, R. Merino-Guzman, X.Hernandez-Velasco, R. Castillo. R. Rodrignez, G. TellezIsais, 2020. Evaluation of oral administration of Lactobacillus plantarum CAM6 Strain as an Alternative to antibiotics in weaned pigs.

Celiberto, L.S.; Bedani, R.; Rossi, E.A.; Cavallini, D.C., 2017.Probiotics: The scientific evidence in the context of inflammatory bowel disease. Crit. Rev. Food Sci. Nutr.,57, 1759-1768.

Danchev, Y., 1984. The aboriginal primitive breed of Eastern Balkan pig Strandzha. Strandzha-Sakar collection, Malko Tarnovo,2. (BG)

Giang, H. H.,Viet, T.Q., Ogle, B., 2010. Lindberg, J.E. Growth performance, digestibility, gut environment and health status in weaned piglets fed a diet supplemented with potentially probiotic complexes of lacticacid bacteria. Livest. Sci., 129, 95-103.

Hossain, M. I., Sadekuzzaman, M.,Ha, S. D., 2017. Probiotics as potential alternative biocontrol agents in the agriculture and food industries: A review. Food Res. Int., 100, 63-73.

Kanev, D., N. Palova, Y. Marchev, S. Ivanova-Peneva, 2013. Influence of waste products from the alcohol industry on the feeding of suckling pigs of the East Balkan breed. Bulgarian Journal of Animal Husbandry, 1, 6, 16-20. (BG) 
Palova, N. 2009. Study on the weight development of pigs of the Eastern Balkan breed depending on sex and season at two levels of protein.Bulgarian Journal of Veternary medicine, 12, suppl., 1, 130-134.

Palova, N., R. Nedeva, K. Stoeva, Y. Marchev, 2011. Influence of different feed types on the productivity of growing pigs from the East Balkan breed. Bulgarian Journal of Animal Husbandry, 6,95-98. (BG)

Shon, KS, Hong JW, Kwon OS, Min BJ, Lee WB, Kim IH, Park YH, Lee IS, 2005. Effects of Lactobacillus reuteri-based direct-fedmicrobial supplementation for growing-finishing pigs. Asian-Aust. J. Anim. Sci. 18:370-374.

Zhao, P., Kim, I., 2015.Effect of direct-fedmicrobial on growth performance, nutrient digestibility, fecal noxious gas emission, fecal microbial flora and diarrhea score in weanling pigs. Anim. FeedSci. Technol., 200, 86-92. 